\title{
Olhares, pensamentos e ações de jovens indígenas Guarani e Kaiowá da Reserva Indígena de Dourados, Estado de Mato Grosso do Sul, Brasil
}

\section{Miradas, pensamientos y acciones de jóvenes Guarani y Kaiowá de la Reserva Indígena de Dourados, Estado de Mato Grosso do Sul, Brasil}

\author{
Views, thoughts and actions of young indigenous Guarani and \\ Kaiowa of the indigenous Reserves of Dourados, State of Mato \\ Grosso do Sul, Brazil
}

Rosely A. Stefanes Pacheco ${ }^{1}$
roselystefanes@gmail.com

Gilmar Ribeiro Fernandes ${ }^{2}$ gilmaradvocacia@hotmail.com

Tiago Fernando Aquino Soares ${ }^{3}$ tiagoaquinosoares@gmail.com

\section{Carlos Gabriel Stefanes Pacheco ${ }^{4}$ gabrielstefanes@yahoo.com.br}

Forma sugerida de citar: Stefanes Pacheco, Rosely A., Ribeiro Fernandes, Gilmar, Aquino Soares, Tiago Fernando, \& Stefanes Pacheco, Carlos Gabriel (2016). Olhares, pensamentos e ações de jovens indígenas Guarani e Kaiowá da Reserva Indígena de Dourados, Estado de Mato Grosso do Sul, Brasil. Universitas, XIV(1), pp. 225-243.

1 Doutoranda em História, UFGD (Universidade Federal da Grande Dourados); Aluna do Programa para Doutorado em Direito UBA (Universidad de Buenos Aires); Professora Curso de Direito UEMS (Universidade Estadual de Mato Grosso do Sul); Membro Centro de Estudos e Pesquisa: Educação, Gênero, Raça e Etnia - CEPEGRE/UEMS/CNPQ.

2 Acadêmico indígena Guarani, $4^{\circ}$ ano, Curso de Direito UEMS (Universidade Estadual de Mato Grosso do Sul).

3 Acadêmico indígena Terena e Guarani Kaiowá, $2^{\circ}$ ano, Curso de Direito UEMS (Universidade Estadual de Mato Grosso do Sul).

4 Acadêmico $1^{\circ}$ ano, Curso de Direito UNIGRAN e Relações Internacionais UFGD (Universidade Federal da Grande Dourados). 


\title{
Resumo
}

O presente texto propõe uma reflexão sobre o processo de participação política dos jovens indígenas Guarani e Kaiowá da Reserva Indígena de Dourados, Estado de Mato Grosso do Sul, Brasil. Um dos objetivos é descrever a partir da análise das iniciativas de ações deste "novo sujeito político", autodenominado de "adolescentes e jovens indígenas", sobre o processo de articulação e mobilização, diante de uma situação de extrema violência a que foram submetidos. Estes sujeitos estão dialogando, sobretudo, com o espaço virtual, ilustrado pelas redes sociais na rede mundial de computadores. Utilizam estas novas tecnologias em favor da luta de seu povo na busca pela efetivação de seus direitos fundamentais. Desta forma, as ações destes jovens e adolescentes indígenas, destacam-se em movimentos de resistência e passam a estabelecer seu protagonismo.

\section{Palavras chave}

Jovens indígenas, participação política, movimento indígena, conflitos sociais, Guarani e Kaiowá.

\begin{abstract}
The present text proposes a reflection on the process of political participation of young indigenous Guarani Kaiowá from the Indigenous Reserve of Dourados, Mato Grosso do Sul, Brazil. One of the objectives is to describe, reflect from the analysis of actionsand initiatives of this "new political subject" calling itself the "indigenous adolescents and young people," on the process of coordination and mobilization, in a situation of extreme violence they have undergone. These subjects are in dialogue, especially with the virtual space, illustrated by social networks on the World Wide Web. They use mainly these new technologies in favor of the fight of their people in the quest for fulfilment of their fundamental rights. Thus, the actions of these young people and indigenous adolescents stand in resistance movements and begin to establish their role.
\end{abstract}

\section{Keywords}

Indigenous youth, political participation, indigenous movement, social conflicts, Guarani Kaiowá.

\section{Resumen}

El presente texto propone una reflexión sobre el proceso de participación política de los jóvenes indígenas Guaraní Kaiowá de la Reserva Indígena de Dourados, Estado de Mato Grosso do Sul, Brasil. Uno de sus objetivos es describir, a partir del análisis de iniciativas y acciones de este "nuevo sujeto político" autodenominado como "adolescentes y jóvenes indígenas", sobre el proceso de articulación y movilización frente a la situación de extrema violencia a que fueron sometidos. Estos sujetos están dialogando, sobre todo, en el espacio virtual, ilustrado por las redes sociales en la red mundial de Internet. Utilizan, estas nuevas tecnologías a favor de la lucha de su pueblo tras la concretización de sus derechos fundamentales. De esta manera, las acciones de estos jóvenes y adolescentes indígenas, se destacan en movimientos de resistencia y pasan a establecer su protagonismo.

\section{Palabras clave}

Jóvenes indígenas, participación política, movimiento indígena, conflictos sociales, Guaraní Kaiowá. 


\section{Considerações iniciais}

Como bem pontuado por Wolkmer (2003), a sociedade mundial tem vivenciado, nas últimas décadas, profundas e significativas mudanças. Assiste-se o desvelar complexo de novos processos e potencialidades criadoras, capazes de instaurar direções múltiplas que favorecem representações conceituais, fluxos diferenciados e ações de cunho coletivo que colocam em evidência atores sociais, portadores de novas subjetividades. Neste processo estão inseridos os povos indígenas e, em especial, conforme destacaremos neste trabalho, os jovens e adolescentes indígenas.

Assim, iniciamos esta reflexão com o seguinte questionamento: o que considerar em um processo de estudo no qual a questão principal é a análise sobre a emergência de um "novo sujeito político", autodenominado "adolescentes e jovens indígenas"? Inferimos esta questão a partir do estudo das ações dos jovens indígenas da Reserva Indígena de Dourados, localizada no Estado de Mato Grosso do Sul, Brasil.

Destacamos que este texto faz parte de um Projeto de Pesquisa ${ }^{5}$ em andamento junto aos jovens indígenas da Reserva de Dourados. Projeto este que tem entre seus objetivos compreender as ações coletivas dos jovens e adolescentes indígenas, frente à violência a que foram submetidos no decorrer do processo histórico. Ademais, entende-se importante compreender a luta política destes jovens indígenas na busca da efetivação de seus direitos fundamentais no contexto contemporâneo de cidadania, bem como tentar diagnosticar os principais problemas que afligem estes jovens.

\section{Algumas considerações sobre os povos indígenas no Brasil}

De acordo com o Censo 2010, do Instituto Brasileiro de Geografia e Estatísticas (IBGE), o Brasil tem 896,9 mil indígenas em todo o território nacional. Desse número, $(63,8 \%)$ corresponde a população residente em terras indígenas, e, nas cidades (36,2\%). Também o Censo 2010 investigou

5 Projeto de Pesquisa realizado junto com acadêmicos indígenas e não indígenas, que se encontra em andamento junto a UEMS- Universidade Estadual de Mato Grosso do Sul, (CEPEGRE- Centro de Pesquisa Gênero, Raça e Etnia, CNPQ). 
o número de etnias indígenas, encontrando aproximadamente 305 etnias, e, identificou 274 línguas $^{6}$.

O Estado de Mato Grosso do Sul apresenta uma população indígena, estimada em aproximadamente 71 mil pessoas. Dentre estes povos indígenas temos: Terena, Ofayé, Kadiwéu, Guató, Guarani, Kaiowá, Kinikinau, Chamacoco e os Kamba. Dentre os grupos indígenas que compõem o Estado, os Kaiowá, os Guarani e os Terena apresentam-se como o maior contingente populacional, somam cerca de 68 mil pessoas, e constituem em termos quantitativos duas das mais importantes populações do país ${ }^{7}$.

Destaca-se que os povos indígenas, hoje localizados neste Estado, em décadas recentes, ocupavam territórios historicamente distintos. Com a chegada das diversas frentes de ocupação e colonização iniciou-se um processo de perda progressiva destes territórios, que passaram a ser ocupados pelas chamadas "frentes de expansão". Neste processo, de expropriação dos territórios, o governo brasileiro demarcou, no início do século XX, pequenas extensões de terra, denominadas de Reservas ou aldeamentos indígenas, com o objetivo de liberar o restante das terras para a colonização. Nesse quadro, com uma situação desfavorável para a sobrevivência física, étnica e cultural, a partir da década de 1980, diversas comunidades Guarani Kaiowá iniciaram ações

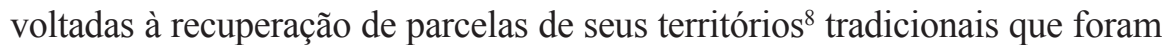
obrigados a abandonar em um passado recente.

\section{Sobre a Reserva Indígena de Dourados ${ }^{9}$}

A Reserva Indígena de Dourados foi criada pelo Serviço de Proteção ao Índio $\left(\mathrm{SPI}^{10}\right)$, em 1917, por meio do Decreto Estadual n. 401 de 1917, com

\footnotetext{
6 Números que põem sofrer alterações.

7 Cf. dados da FUNASA-2010 (www.funasa.gov.br).

8 Nesse sentido ver Stefanes Pacheco (2004).

9 Nos termos da legislação vigente (CF/88, Lei 6001/73 - Estatuto do Índio, Decreto n. $\left.{ }^{\circ} 1775 / 96\right)$, as terras indígenas podem ser classificadas em diversas modalidades e uma delas é o tipo de Reserva Indígena que corresponde: terras doadas por terceiros, adquiridas ou desapropriadas pela União, que se destinam à posse permanente dos povos indígenas. São terras que também pertencem ao patrimônio da União, mas não se confundem com as terras de ocupação tradicional. Observa-se que um dos problemas da área indígena objeto deste estudo é que esta não corresponde com a demanda original dos Guarani Kaiowá. Foi implantada unicamente por ação do Estado brasileiro, sem levar em consideração anseios do grupo étnico.

10 SPI (Serviço de Proteção ao Índio) correspondia ao órgão tutelar da época que orientava às políticas para os povos indígenas.
} 
3.600 ha. Entretanto, o título definitivo da área, legalizada como patrimônio da União, foi emitido somente em 1965. (Monteiro, 2003).

Conforme destaca Pereira (2014, p. 3), a Reserva Indígena de Dourados demarcada pelo SPI no início do século XX, foi transformada em área de acomodação de famílias indígenas oriundas de dezenas de comunidades das etnias Kaiowá, Guarani e Terena. Em menor número, a reserva agregou também paraguaios e regionais brasileiros, incorporados por casamentos interétnicos.

Diante desta política implementada pelo Estado brasileiro, atualmente, na Reserva vivem as etnias Kaiowá, Guarani e Terena ${ }^{11}$. Todas mantêm espaços de manifestação de suas identidades étnicas, sempre baseadas em elementos, de organização social, de religião e outros componentes da tradição cultural. Entretanto, segundo Pereira (2014), isto não significa que cada uma dessas tradições culturais se manteve inalterada no tempo.

Nesta área convivem, atualmente, uma população de mais de doze mil pessoas. No decorrer do processo histórico, missões, escolas, programas econômicos, de assistência social e de saúde, se empenharam por décadas em incorporar os indígenas à população regional, esforço sempre inconcluso.

\section{Violência e povos indígenas}

Sabe-se que a violência contra os povos indígenas no Brasil é recorrente e assustadora, e tem se repetido ao longo dos anos ${ }^{12}$. E, neste contexto se encontram inseridos os Guarani e Kaiowá, do Estado de Mato Grosso do Sul, que têm experimentado uma história de exclusão e desconsideração de seus direitos e garantias fundamentais.

Conforme expõe Eremites de Oliveira (2012):

[...] por mais absurdo que possa parecer, no Brasil há quem avalie -não sem dados para isso- que em Mato Grosso do Sul está em andamento uma política genocida de promover uma espécie holocausto contra os Guarani e Kaio-

11 Segundo Pereira (2014) a Reserva Indígena de Dourados, além dessas três etnias já citadas, também abriga pessoas indígenas de outras origens étnicas, como Bororo e Kadiweu, além de alguns poucos regionais (brasileiros e paraguaios), normalmente agregados a parentelas indígenas, por terem contraído casamentos com membros de uma das etnias que vivem na Reserva Indígena.

12 Para tanto ver o Relatório de Violência contra os Povos Indígenas no Brasil (CIMI), 2014, disponível em: http://www.cimi.org.br/site/pt-br/?system=publicacoes\&cid=30, acesso em 20 de fevereiro de 2016. 
wá, muitos dos quais vivem em reservas indígenas superlotadas que lembram campos de concentração. Nesses espaços a dignidade da pessoa humana é desrespeitada de várias formas. Há, ainda, comunidades estabelecidas em acampamentos às margens de rodovias em condições igualmente indignas, muitas vezes sem acesso à água potável, alimentação decente, educação formal e saúde de qualidade [...], Muitas esperam por decisões do Estado brasileiro sobre áreas que reivindicam como terras tradicionalmente ocupadas por comunidades indígenas. Somam-se a isso os muitos assassinatos de lideranças indígenas, registrados ano após ano (Eremites de Oliveira, 2012).

Segundo o Relatório Brief Report on the violations of the Human Rights of the indigenous Kaiowá Guarani peoples in Mato Grosso do Sul - Brazili, produzido pelo CIMI (Conselho Indigenista Missionário) para divulgação da situação de violência contra os povos indígenas no Brasil, publicado em 2014:

The data gathered in this Report indicate an increase in violations of human rights in general and, specifically, in suicide and murder cases. In the year of 2014, there were 135 suicides, most of them committed by youngsters. Forty-eight of those cases happened in Mato Grosso do Sul alone. Considering records from between 2000 and 2014, only in that state, we find an alarming number of 707 suicides $^{14}$.

Inseridos neste contexto de violência estão os jovens indígenas, e segundo Martini (2015):

Los adolescentes y jóvenes pobres padecen las mayores violencias, son los que coronan las estadísticas sobre la muerte, lugar del sufrimiento y la tragedia. Esa información es escamoteada, el ocultamiento que practican las instituciones involucradas y algunos sectores de la opinión pública se reiteran en las agendas de los medios de monopolios donde, cuando son invisibilizados, sufren la discriminación y criminalización por jóvenes, por pobres, por villeros.

13 Disponível em: http://www.cimi.org.br/pub/Kaiowaguaranibriefreport.pdf, acesso em 02 de fevereiro de 2016.

14 Tradução livre: Os dados recolhidos neste Relatório indicam um aumento nas violações dos direitos humanos, especificamente, em suicídios e assassinatos. No ano de 2014, houve 135 suicídios, a maior parte cometida por jovens indígenas. Quarenta (40) desses casos aconteceram no Estado de Mato Grosso do Sul. Considerando os registros entre 2000 e 2014, apenas nesse Estado, encontramos o número alarmante de 707 suicídios. 
De acordo com o autor, estes são discursos que: "los hacen invisibles a la pobreza mostrando como una esencia, una condición inherente y natural a ciertos sectores sociales, que deberían soportarla, y quizás con esfuerzo lograrían revertirla" (Martini, 2015, p. 65).

Entendemos a violência como a coação moral, emocional, física e psicológica que uma pessoa exerce sobre outra. Tal definição contempla o que foi definido pela Organização Mundial de Saúde (OMS, 2002):

El uso deliberado de la fuerza física o el poder, ya sea en grado de amenaza o efectivo, contra uno mismo, otra persona o un grupo o comunidad, que cause o tenga muchas probabilidades de causar lesiones, muerte, daños psicológicos, trastornos del desarrollo o privaciones.

Segundo Pueyo (2012, p. 200), "se puede asentar que la violencia es una estrategia que ponen en marcha individuos o grupos para alcanzar un fin determinado". Diante disso, compreende-se que a violência pode assumir múltiplas configurações e abarcar diversas manifestações. E, nos últimos anos, sem dúvidas uma de suas modalidades que tem marcado a vida dos jovens e adolescentes indígenas é a violência social.

\section{Das demandas e a participação dos jovens indígenas}

A partir de dados coletados na pesquisa de campo, tem-se que os problemas sociais se agravaram nas últimas décadas entre os Guarani e Kaiowá, com destaque para os casos de suicídios envolvendo, sobretudo, a parcela mais jovem da população nas aldeias Jaguapirú e Bororó, da Reserva Indígena de Dourados. Além disso, destacamos o aumento do consumo de bebida alcoólica e drogas ilícitas, bem como dos conflitos entre grupos de adolescentes e jovens, o que se tornou uma preocupação das instituições ligadas ao controle social como a polícia e o conselho tutelar ${ }^{15}$.

Um dos entrevistados, jovem Guarani morador da Aldeia Jaguapirú, assim declarou ${ }^{16}$ :

15 O conselho tutelar foi criado conjuntamente ao ECA (Estatuto da Criança e do Adolescente), instituído pela Lei 8.069 no dia 13 de julho de 1990. Órgão municipal responsável por zelar pelos direitos da criança e do adolescente.

16 Inicialmente foram realizadas entrevistas com quatro jovens, por entendermos que essa forma de coleta de dados possibilita a apreensão da percepção dos sujeitos em relação às suas próprias ex- 
Às vezes nos sentimos sem esperança. Por quê? Porque não percebemos que as grandes empresa e indústrias de cana de açúcar estão nos sufocando cada dia, plantando cana e soja em volta da aldeia, intoxicando as criança com o veneno, causando grandes epidemias de doença, como gripe, diarreia, dores de cabeças e poluindo o nosso nascente.

Um segundo entrevistado, jovem Kaiowá, também morador da aldeia Jaguapirú, quando relata sobre os problemas enfrentados por eles, assim argumenta:

Muitos jovens, por causa de falta de oportunidade partem para mundo sem volta, que é bebida, drogas e acabam perdendo a vida. Isso que nós não queremos, vendo tudo isso a gente fica com medo, e perdemos a esperança, Por favor, alguém pode ajudar, pois, devagar o jovem está se perdendo nas terríveis misérias da marginalização.

Pereira (2014) destaca que, além do problema da desnutrição que assolou a Reserva em décadas recentes e que foi amplamente divulgado pela mídia, esta Reserva Indígena ficou muito conhecida em âmbito nacional por apresentar graves problemas sociais, falta de espaço físico, superpopulação, índices elevados de violência, falta de acesso à educação de qualidade, água potável, dentre outros. O autor argumenta que "a nova geração de lideranças se empenha em resolver tais problemas, mas as soluções sempre esbarram em dificuldades de contar com o necessário apoio das instituições estatais" (Pereira, 2014, p. 22).

$\mathrm{O}$ autor identifica que:

Inexiste uma política indigenista que proponha ações efetivas e adequadas para a resolução de tais problemas. O principal desafio é encontrar alternativas de formação, ocupação e geração de renda para o grande número de jovens na RID. A despeito do alto índice de mortalidade infantil e mortes de jovens por violência (Pereira, 2014, p. 22).

Ainda acrescenta que:

Afora estes graves problemas, na RID existem poucas oportunidades de lazer para as pessoas, especialmente para os jovens. Várias lideranças asso- 
ciam o alto índice de violência à ausência de políticas de esporte e lazer voltadas para as crianças e para a juventude indígena ${ }^{17}$. É comum também expressarem que as formas de diversão, como rituais religiosos, chichas ${ }^{18} \mathrm{e}$ bailes, são pouco praticados e não atraem mais a atenção dos jovens na atualidade (Pereira, 2014, p. 23).

No entanto, mesmo diante desta situação desfavorável, avultam-se movimentos de resistência, e, dentre eles, destacam-se as vozes dos jovens e adolescentes indígenas, que, mesmo diante das dificuldades encontradas, não se calaram e passaram a estabelecer seu protagonismo.

De acordo com Cabrero (2013):

Gracias a su estructuración comunal de resistencia, los pueblos indígenas han sido y continúan siendo actores clave para mejorar y ampliar el concepto y la práctica de la democracia, haciendo avanzar así la democracia de ciudadanía hacia nuevos horizontes interculturales. (Cabrero, 2013, p. 79).

Ademais, como anota Stefanes Pacheco (2004), diferentes grupos humanos habitam o território nacional, originando variadas configurações socioculturais. Inseridos neste contexto estão os povos indígenas que desde há muito tempo têm vivenciado inúmeros conflitos, onde se observa a violência e a intolerância. Em larga medida, suas respostas têm sido o clamor pelo respeito e a necessidade de negociação da convivência com a diferença.

$\mathrm{Na}$ realidade, o que podemos observar é que cada vez mais comunidades estão reivindicando espaços e se fazendo presentes, percebemos dentro de um contexto maior, ou seja, global, que as comunidades estão cada vez mais se organizando de acordo com suas especificidades. E, neste contexto, os povos indígenas querem ser escutados a partir de um local determinado, como indígenas, participando de um processo histórico que, ao contrário do

17 Sobre o tema da violência e jovens indígenas, destacamos que estamos buscando para o Projeto de Pesquisa, dados junto aos órgãos e instituições responsáveis, para conhecermos melhor sobre a questão. Dentre os órgãos destacamos as delegacias de polícia, Ministério Público federal, CRAS, dentre outros. Procuraremos, por exemplo, identificar o número de adolescentes que cometeram suicídio desde 2010, bem como tentaremos verificar o número de homicídios tendo os adolescentes tanto enquanto vítimas, como também enquanto autores.

18 Chicha se refere a bebida fermentada de milho, batata, mandioca ou frutas como guavira e jabuticaba. Essas bebidas eram consumidas nos intervalos de cantos e danças guachiré (guahu, kotihu). Embora essas danças sejam exclusivas dos Kaiowá e Guarani, até algumas décadas era comum que todos os moradores da RID participassem de tais eventos festivos, assim como dos bailes, quando se tocava e se cantava músicas regionais ou fronteiriças (Pereira, 2014, p. 23). 
que já foi prognosticado, apresenta-se como um campo aberto de possibilidades (Stefanes Pacheco, 2004, p. 19).

Portanto, diante da violência como "un quebrantamiento intempestivo, una destrucción de las identidades, una experiencia de devastación de vida o una exigencia de la reconstrucción radical de la propia experiencia", se insurge com uma meridiana centralidade a questão da voz, enquanto protagonismo dos jovens e adolescentes indígenas.

Un alzamiento sincero, abierto, insurrecto que demanda escucha y clama por la justicia ante un orden poderoso, y a menudo violento, que puede aplastarlo. La violencia, como experiencia individual y social da lugar a la construcción de una ética de la no violencia que se nos propone desde el mundo infanto adolescente, una ética de convivencia, de respeto, de escucha, surgida de la reflexión acerca de la tensión, el dolor, la tristeza, el abandono y la fractura. (Bustelo, 2007 apud Mateos, 2015, p. 17).

\section{Breves considerações sobre as "categorias" adolescentes e jovens indígenas}

Importante destacar que a categoria, adolescente e jovem indígena, é utilizada neste texto enquanto categoria "re-apropriada" e ou "re-significada" por esses agentes sociais. Essa categoria deve ser entendida enquanto expressão do próprio movimento indígena, nascido no contexto atual, e que se expressa enquanto discurso apropriado por um grupo específico.

Segundo Vale e Rangel (2008), a categoria jovem indígena está dentro de um quadro mais amplo de direitos coletivos dos povos indígenas nas Américas, e, na América Latina em particular, uma vez que que, há países que são de maioria reconhecidamente indígena. Assim, pode-se interpretar que a categoria jovem indígena pode ser considerada enquanto uma categoria em transição ou em construção.

Ainda, de acordo com as autoras, se considerarmos sob a ótica interna dos povos indígenas, em cada ambiente social observa-se a construção de categorias de idade que variam estrutural e culturalmente, apresentando-se com uma diversificação bastante relevante. Além do que, os estudos antropológicos e as etnologias, elaborados em campo, demonstram que as categorias de idade são afeitas de acordo com o status social que os indivíduos adquirem ao longo da vida, podendo sofrer alterações de acordo com as etnias. (Vale e Rangel, 2008). 
Com relação à organização social dos Guarani e Kaiowá, estudos antropológicos, dentre eles, Meliá, 1978; Thomaz de Almeida, 1991; Mura, 2000, destacam que os Guarani Kaiowá, Nandeva e Mbya continuam hodiernamente sua organização social centrada na família extensa.

No passado, uma família extensa indígena composta por mais de uma centena de indígenas vivia dentro de uma casa grande, sendo que nesta habitação e no seu entorno os adultos trabalhavam, juntamente com os jovens e as crianças, sendo as atividades cotidianas divididas segundo o gênero e a idade. Com o passar do tempo, ocorreu o desaparecimento da casa grande, entretanto, isto não significou uma mudança na centralidade desta organização social.

No seio da família extensa Guarani e Kaiowá, as crianças maiores cuidam das menores, de maneira que todas são "educadas" juntas nestes espaços compartilhados, por meio de práticas que servem para todas as crianças, que acontecerá até os 13 anos de idade. Isto porque, esta é a fase final do período que corresponde ao "ser criança” entre os Guarani e Kaiowá (Benites, 2014).

Portanto, pode-se considerar que a fase do jovem e adolescente se inicia a partir dos 14 anos de idade; para o menino ocorre com a mudança de voz e para a menina com a primeira menstruação. Neste processo, passam para outra fase, ainda não adultos, mas se preparando para a fase adulta, o que ocorre mais ou menos após os 14 anos de idade. Neste momento, com a "mudança" de voz, o menino é liberado pela mãe e a avó para acompanhar os homens da aldeia nos seus afazeres diários (Benites, 2014).

$\mathrm{O}$ mesmo autor acrescenta que um processo semelhante é realizado com a menina, mas obviamente de modo distinto e mais rígido. Entre as restrições, aponta-se que após a primeira menstruação, a menina não deve mais interagir sozinha com qualquer menino com idade superior a ela. A primeira menstruação é marco fundamental para a menina se tornar jovem, iniciando a fase adulta, devendo permanecer sob orientação da avó e da mãe ao longo do processo de experiência adulta.

\section{Das ações dos jovens e adolescentes indígenas na Reserva Indígena de Dourados}

Sobre as ações coletivas dos jovens e adolescentes indígenas, deve-se destacar que existem Ongs e associações indígenas que possuem um trabalho específico de apoio aos jovens indígenas no Estado de Mato Grosso do 
Sul e em diversas outras regiões do país (Vale e Rangel, 2008). Percebe-se que a preocupação com essa categoria começa a ganhar notoriedade e a palavra dos jovens passa a ter lugar de destaque em encontros, conferências e seminários que congregam indígenas.

Na Reserva Indígena de Dourados, a mobilização de adolescentes e jovens indígenas ocorre no entorno de grupos de jovens, como exemplo a AJI (Ação dos Jovens Indígenas de Dourados). ${ }^{19}$ Esses coletivos de jovens se aglutinam em torno da busca de alternativas para os jovens inseridos em situação social de risco.

Entre os objetivos da AJI está o de fortalecer a socializar informações entre as etnias que compõe a Reserva Indígena de Dourados, tida como a mais populosa do país. A sede da AJI está localizada no município de Dourados, que está distante $04 \mathrm{~km}$ (quatro quilômetros) da Reserva Indígena.

Além de alguns coletivos de jovens indígenas, é importante também destacar o protagonismo destes nas redes sociais. Benites (2014), em seu estudo sobre a luta política inédita dos jovens indígenas através das redes sociais e a busca e efetivação de seus direitos fundamentais no contexto contemporâneo, expõe que, historicamente, a manifestação e as reivindicações dos povos indígenas pelo reconhecimento de seus direitos e, sobretudo, pela defesa e recuperação de seus territórios tradicionais eram apresentadas na mídia com componentes carregados de preconceitos e estereótipos, tidos como violentos e portadores de ilegalidade.

Como o próprio autor afirma, é importante destacar que estas representações e descrições dos indígenas acabaram se tornando a visão dominante na sociedade envolvente. Esta passou a ser divulgada de forma naturalizada pela mídia ${ }^{20}$. Diante deste processo, destaca-se que as lideranças indígenas, tinham dificuldades de contrapor a essa "situação" imposta pela mídia e que apresentava-se como a única verdade possível (Benites, 2014: 6).

Diante desta situação, Benites (2014) acrescenta que, em 2011, a pedido da assembleia geral dos povos indígenas (Aty Guasu) ${ }^{21}$, se formou uma

19 A AJI (Ação dos Jovens Indígenas de Dourados) é uma Organização indígena de jovens financiada com capital privado. Fundada em 2001 pela antropóloga Maria de Lourdes Beldi de Alcântara junto com jovens Guarani-Kaiowá e Aruak.

20 Nesse sentido ver a Análise Crítica de Discurso de Teun Van Dijk (2008), que nos permite, por meio da integração de diferentes disciplinas, estudar como as estruturas de poder, dominação e desigualdade dentro de uma sociedade são reproduzidas através do texto e da fala.

21 Aty Guasu, são as grandes assembleias realizadas pelos Guarani e Kaiowá. 
comissão de líderes jovens indígenas para contrapor e desconstruir as informações "tendenciosas" e preconceituosas sobre estes povos. A tarefa consistia em divulgar a situação atual e às demandas efetivas dos indígenas, em especial daqueles que se encontravam em situações de conflitos fundiários. E, uma das ferramentas utilizadas por estes jovens para tal propósito passou a ser o uso das redes sociais em favor das demandas.

Assim, os jovens Guarani e Kaiowá começaram a utilizar as redes sociais, por meio do Facebook e de blogs. Neste momento, um grupo de jovens criou o endereço eletrônico do Aty Guasu no Facebook (página que já possui milhares de contatos). Esse endereço eletrônico se tornou um boletim informativo, tanto dos jovens como das lideranças Guarani e Kaiowá.

Este endereço virtual passou a ser um canal de divulgação importante de informações diretas das comunidades indígenas dos territórios que se encontravam em conflito fundiário, e, a partir de então passaram a utilizar mais ativamente seus aparelhos de celular, enviando e-mails e procurando contatar membros da comissão dos jovens indígenas, informando-lhes problemas que mais os afligiam, dentre eles os ataques sofridos por terceiros, ameaças, dentre outros.

Portanto, um dos principais objetivos da criação do endereço da assembleia geral indígena (Aty Guasu) na rede social é divulgar as informações, contextualizando-as, apresentando-as pelos próprios indígenas que participam deste processo. Neste endereço eletrônico são traduzidas para o idioma português e disponibilizadas pelos jovens indígenas as notas públicas das lideranças, os documentos escritos destinados às autoridades competentes do Estado brasileiro, as petições, as fotografias, os vídeos resultantes de encaminhamentos e discussões internas. De maneira geral, procuram com estas ações socializar as informações. Além disso, os conteúdos divulgados neste endereço do Aty Guasu via Facebook e em blogs são exclusivamente de autoria dos indígenas e ficam acessíveis a todos os indígenas e não indígenas que acessam a rede mundial de computadores.

Evidenciou-se que, ao longo de todo o ano de 2012, por meio de seu endereço virtual, as lideranças indígenas, passaram a divulgar diretamente as violências promovidas por alguns proprietários de terras contra o povo Guarani e Kaiowá nos territórios em conflito. Em decorrência dessa divulgação, que relatou muitos episódios de violência e assassinatos de lideranças indígenas, milhares de cidadãos(ãs) acrescentaram a identificação "Guarani e Kaiowá" como os seus sobrenomes nas redes sociais. Somando-se a isso, 
procuraram promover atos públicos em diversas cidades do país, tornandose uma manifestação nacional. Esse ato de protesto e resistência contra a situação vivida pelos Guarani Kaiowá no Brasil, também foi realizado por brasileiros residentes em outros países.

Como é possível perceber, essas ações perpetradas pelos jovens indígenas foi algo inédito, não só para o contexto do Estado de Mato Grosso do Sul, mas também para todo o país, inclusive em âmbito internacional. A partir dessas ações, a sociedade envolvente passou conhecer de forma mais incisiva a situação a que são submetidos os Guarani e Kaiowá no Estado de Mato Grosso do Sul (Benites, 2014).

Dessa maneira, uma das experiências importantes dos jovens indígenas, hoje, é a utilização das novas tecnologias em favor de seu povo. A nova geração Guarani e Kaiowá deseja saber ler e escrever tanto na língua indígena materna, quanto na língua portuguesa (bilíngue), mas também deseja dominar as ferramentas da informática e internet, pois entendem que são conhecimentos importantes para as lutas contemporâneas que vêm enfrentando.

Segundo Benites (2014):

Os jovens indígenas tomaram também o aprendizado de leitura, escrita e informática como um desafio, pois muitos não índios duvidavam e duvidam que indígenas pudessem ler, escrever, dominar a nova tecnologia e internet, dizendo que ler, escrever bem, dominar a informática e internet não eram coisa de "índio". Diante disso, os jovens Guarani e Kaiowá decidiram lutar contra o preconceito e o estigma, e aceitaram o desafio. Essa luta foi um dos assuntos avaliados e debatidos amplamente no encontro dos jovens indígenas (Benites, 2014, p. 8).

\section{Da importância dos direitos para jovens e adolescentes indígenas}

No Brasil, as crianças e os adolescentes receberam atenção e tratamento diferentes no decorrer da história da sociedade brasileira. A década de 1980, em particular, foi fundamental para a construção da noção que se tem hoje, sobre a população infanto-juvenil. A Constituição Federal, promulgada em outubro de 1988, significou um grande avanço nos direitos sociais, e isto por sua vez beneficiou, entre outros, a criança e o adolescente. $\mathrm{O}$ auge desse processo de conquista e garantias de direitos fundamentais foi, sem dúvida, 
a aprovação do Estatuto da Criança e do Adolescente (Lei 8.069, de 13 de julho de 1990).

Diante dessas legislações, crianças e adolescentes, considerados enquanto sujeitos de direitos, têm sido o foco de diversas ações e mobilizações na sociedade, na perspectiva de sua proteção. Destaca-se que, situações envolvendo maus tratos, abuso e exploração, por exemplo, mobilizam segmentos sociais para o seu enfrentamento, coibição e modificação. Entretanto, há de se considerar que estas são legislações de cunho geral, não contemplam na maioria das vezes os anseios e demandas das populações indígenas ${ }^{22}$.

Em âmbito internacional destaca-se que em setembro do ano 2000, baseando-se na década das grandes conferências e encontros das Nações Unidas, líderes mundiais se reuniram na sede das Nações Unidas, em Nova York, para adotar a Declaração do Milênio da ONU (Organização das Nações Unidas).

Com esta Declaração, as Nações se comprometeram a uma nova parceria global para reduzir a pobreza extrema, em uma série que contemplava oito objetivos - com um prazo para realização que seria o ano de 2015- que se tornaram conhecidos como os Objetivos de Desenvolvimento do Milênio (ODM). Dentre as metas do milênio, sobressaiu a redução da pobreza, da desigualdade, bem como a promoção do exercício do direito a participação na vida coletiva da sociedade.

Apesar do prazo estipulado, este não foi levado em consideração, pois, o ano de 2015 se findou, e, apesar de alguns esforços empreendidos para o cumprimento dos Objetivos do Desenvolvimento do Milênio, que seria garantir o bem estar igualitário para todas as crianças e adolescentes, muito ainda há que ser realizado.

Apesar do relatório de 2015 estampar em suas páginas: “O Brasil, país multicultural situado nos trópicos, alcançou resultados espetaculares em termos de desenvolvimento humano e tem se tornado um exemplo para o mundo com suas políticas sociais consideradas extraordinárias e inovadoras", temos que considerar que nem todos os povos foram beneficiados com estas políticas.

22 Para tanto, basta observar as difíceis situações enfrentadas pelas crianças e jovens Guarani e Kaiowá, nas Reservas do Estado de Mato Grosso do Sul. Disponível em http://www.survivalinternational.org/povos/guarani, acesso em 02 de fevereiro de 2016. Também há de se destacar a importância de legislações específicas para os povos indígenas. 
Neste contexto, de proteção aos direitos das crianças e adolescentes, o Relatório sobre a Situação Mundial da Infância, publicado em 2011, foi dedicado aos adolescentes, uma vez que era indispensável garantir o exercício dos direitos deste grupo para alcançar as metas do Milênio. O Relatório assim destaca:

Ouvir os adolescentes é a única forma de compreender o que esperam de nós. Trata-se de uma etapa decisiva no crescimento de uma pessoa. Devemos ouvir atentamente as necessidades e preocupações específicas dos adolescentes. Vamos criar oportunidades para que participem na sociedade. Vamos permitir que tenham liberdade e oportunidade para amadurecer e converterse em adultos saudáveis (Relatório UNICEF, 2011, p. 17).

Diante destas considerações, percebe-se que, o direito internacional reconhece e possui mecanismos que devem garantir o direito dos jovens e adolescentes, e, isso constitui uma dimensão fundamental da justiça. Assim, estar à altura desta dimensão significa assegurar que os jovens e adolescentes mesmos possam fazer uso destes direitos.

Conforme pontuou Hannah Arendt (1989), nas sociedades contemporâneas "o direito a ter direitos" e a fazer uso dos mesmos constituiu uma das condições básicas fundamentais de qualquer tipo de justiça. O direito a ter direitos é um conceito fundamental em qualquer conceito de Justiça. Porém, o direito e a lei não são suficientes para garantir que em determinada sociedade exista justiça. Nesse sentido, percebe-se por meio de ações coletivas, que estes direitos têm sido constantemente reivindicados pelos jovens e adolescentes indígenas.

E, segundo Mateos (2015):

Un niño, una niña, un adolescente que habla de violencia, que la discute, que la critica, que la denuncia, es un sujeto político que conoce sus derechos y se autoconstruye como ciudadano en la acción misma de ejercerlos. Si la ciudadanía es un modo de articulación de demandas, de constituir agrupamientos, de desarrollar prácticas sociales y demandas al Estado, el ejercicio específico de ciudadanía infanto adolescente expresa el empoderamiento de Niños y Adolescentes desde el ejercicio de la palabra, de la denuncia, del reclamo por los propios derechos. Esta puesta en cuestionamiento constituye en sí mismo un acto ciudadano: un acto político (Mateos, 2015, p. 17). 


\section{Apontamentos finais}

Como afirma Boaventura de Souza Santos "os desafios, quaisquer que eles sejam, nascem sempre de perplexidades produtivas (...) deveremos começar pelo contexto sócio temporal de que emergem as nossas perplexidades" (2005, p. 17). Entendemos que é essa perspectiva que deve orientar nossos passos, reconhecendo que a discussão sobre os direitos dos jovens e adolescentes indígenas tem uma complexidade que não cabem em respostas prontas.

Diante do que logramos observar até o presente momento, destaca-se que as políticas de jovens ou para os jovens e adolescentes devem conceber este enquanto protagonista de sua história. E, entre outras medidas, deve-se fortalecer seu capital social e de liderança juvenil.

Percebe-se que há entre os jovens e adolescentes indígenas, uma nova geração de políticas que privilegiam as identidades juvenis e sua produção simbólica, com especial ênfase em espaços de encontro de expressão coletiva. Estes buscam aprimorar estas políticas e facilitar dinâmicas de comunicação à distância. Assim, mais além das diversas ideias sobre políticas de juventude que se possa estabelecer, está o desafio de potencializar a dialética que vincula positivamente os danos sofridos por esta categoria, revertendo-os em esperanças e conquistas.

Se trata de trabalhar o desenvolvimento de capacidades e fortalecer mecanismos de proteção e promoção a partir da "escuta da juventude", reconhecê-la como um conjunto de sujeitos de direitos, conferindo direito aos jovens e adolescentes de serem eles(as) mesmos(as) (Hopenhayn, 2015).

As novas gerações estão (re)elaborando uma maneira de assumirem suas identidades étnicas em diálogo com os diversos contextos socioculturais nos quais estão inseridas. Estes sujeitos estão articulando, sobretudo, com o espaço virtual, ilustrado pelas redes sociais na rede mundial de computadores. E, conforme já destacamos no texto, uma das experiências importantes dos jovens indígenas, hoje, é a utilização das novas tecnologias em favor da luta política de seu povo.

Esta nova geração Guarani e Kaiowá deseja saber ler e escrever tanto na língua indígena materna, quanto na língua portuguesa (bilíngue), mas também deseja dominar as ferramentas da informática e internet, pois entendem que são conhecimentos importantes para as lutas contemporâneas que vêm enfrentando. 


\section{Bibliografia}

Arendt, Hannah (1989). Origens do totalitarismo. São Paulo: Cia. das Letras.

Benites, Tonico. (2014). A educação dos jovens Guarani e Kaiowá e sua utilização das redes sociais na luta por direitos. Revista Desidades, 2(2). mar.

Bustelo, Eduardo. (2007). El recreo de la infancia. Argumentos para otro comienzo. Buenos Aires: Siglo XXI.

Dijk, Teun A. Van (2008). Discurso e Poder. São Paulo: Contexto.

Eremites de Oliveira, Jorge (2012). Um holocausto contra os Guarani e Kaiowá em Mato Grosso do Sul? 07 de fevereiro de 2012 http://fronteiraagora.com. br/portal/um-holocausto-contra-os-guarani-e-kaiowa-em-mato-grossodo-sul [02 de fevereiro de 2016].

Hopenhayn, Martín (2015). La juventud latinoamericana. recuento de daños, logros y esperanzas. En: Hernández, Alberto y Campos- Delgado, Amalia E. (Coord.), Actores, redes y desafios: juventudes e infancias en América Latina. Tijuana: El Colegio de la Frontera Norte; Buenos Aires: Consejo Latinoamericano de Ciencias Sociales.

Martini, Stella (2015). Nombrar las violencias. Certezas y paradojas de la opinión pública. En: Martini, Stella e Contursi, María Eugenia (Comp.), Crónicas de las violaciones en la Argentina: Estudios en comunicación y medios. Buenos Aires: Ediciones Imago Mundi.

Mateos, Paula Helena, Merino, María Elena; Berdeguer, Luis Marcelo (2012.) Filosofía con niñas, niños y adolescentes. Libro de trabajo 1er Congreso Nacional y 6to Congreso Provincial de Niños, Niñas y Adolescentes Protagonistas del Cambio Social. Ministerio de Desarrollo Humano de la Provincia de San Juan. Secretaría Nacional de Niñez Adolescencia y Familia. Ministerio de Desarrollo Social. Presidencia de la Nación. Buenos Aires.

Mateos, Paula Helena (2015). Narrativas de la violencia: las voces infanto-adolescentes como parrhesia. Buenos Aires: Clacso.

Melià, Bartomeu; Grunberg, Georg e Grünberg, Fried (1976). Los Paî-Tavyterã: Etnografia guarani del Paraguai contemporâneo. Suplemento Antropológico de la Revista del Ateneo Paraguayo, 9, 1-2.

Mura, Fabio (2000). Habitações Kaiowá: Formas, propriedades técnicas e organização social. Dissertação de mestrado apresentada ao PPGAS do Museu Nacional-UFRJ. Rio de Janeiro, UFRJ.

Organización Mundial de la Salud (OMS) (2002). Informe Mundial sobre la Violencia y la Salud. Resumen. Washington, OPS, disponível em http://www. 
who.int/violence_injury_prevention/violence/world_report/es/summary_es.pdf [20 de janeiro de 2016].

Pereira, Levi Marques (2014). A atuação do órgão indigenista oficial brasileiro e a produção do cenário multiétnico da Reserva Indígena de Dourados, MS. http:// www.anpocs.org/portal/index.php?option=com_docman\&task=doc_ view\&gid=8809\&Itemid=461 [21 de janeiro de 2016.]

Pueyo, Antonio (2012). Presente y futuro de la violencia interpersonal en las postrimerías del estado del bienestar. Revista Anuario de psicología, 4(2), 199-21. Barcelona: Universidad de Barcelona.

Relatório Brief Report on the violations of the Human Rights of the indigenous Kaiowá Guarani peoples in Mato Grosso do Sul - Brazil, CIMI, 2014 disponível em http://www.cimi.org.br/pub/Kaiowaguaranibriefreport.pdf [2 de fevereiro de 2016.]

Relatório Nacional de Acompanhamento dos objetivos de desenvolvimento do Milênio, maio, 2014, IPEA (Instituto de Pesquisa Econômica Aplicada) http://www.pnud.org.br/Docs/5_RelatorioNacionalAcompanhamentoODM.pdf [05 de fevereiro de 2016.]

Relatório sobre a situação mundial da infância, UNICEF, 2011, Adolescência uma fase de oportunidades http://www.unicef.org/brazil/pt/br_sowcr11web. pdf [20 de fevereiro de 2016.]

Santos, Boaventura de Sousa (2005). Pela Mão de Alice. Cortez Editora. 10a . Edição. Thomaz de Almeida, Rubem (1991). O projeto Kaiowá-Ñandéva: uma experiência de etnodesenvolvimento junto aos Guarani-Kaiowá e Guarani-Ñandéva contemporâneos do Mato Grosso do Sul. Dissertação de mestrado apresentada ao PPGAS/Museu Nacional/UFRJ. Rio de Janeiro.

Vale, Claudia Netto do, e Rangel, Lucia Helena (2008). Jovens indígenas na metrópole. Ponto-e-Vírgula, 4, 254-260.

Stefanes Pacheco, Rosely Aparecida (2004). Mobilizações Guarani Kaiowa e Nandeva e a (re) construção de territórios (1978-2003): novas perspectivas para o Direito Indígena. Dissertação de Mestrado em História. Dourados, UFMS.

Wolkmer, Antonio Carlos e Jose Rubens M. Leite (2003). Os "novos" direitos no Brasil. São Paulo: Saraiva.

Fecha de recepción: 20/03/2016; fecha de aprobación: 14/03/2016 